IZA DP No. 4281

Flexible Labor Supply Models

Olivier Bargain

July 2009 


\title{
Flexible Labor Supply Models
}

\author{
Olivier Bargain \\ University College Dublin, \\ CHILD and IZA
}

\section{Discussion Paper No. 4281 July 2009}

\author{
IZA \\ P.O. Box 7240 \\ 53072 Bonn \\ Germany \\ Phone: $+49-228-3894-0$ \\ Fax: +49-228-3894-180 \\ E-mail: iza@iza.org
}

\begin{abstract}
Any opinions expressed here are those of the author(s) and not those of IZA. Research published in this series may include views on policy, but the institute itself takes no institutional policy positions.

The Institute for the Study of Labor (IZA) in Bonn is a local and virtual international research center and a place of communication between science, politics and business. IZA is an independent nonprofit organization supported by Deutsche Post Foundation. The center is associated with the University of Bonn and offers a stimulating research environment through its international network, workshops and conferences, data service, project support, research visits and doctoral program. IZA engages in (i) original and internationally competitive research in all fields of labor economics, (ii) development of policy concepts, and (iii) dissemination of research results and concepts to the interested public.
\end{abstract}

IZA Discussion Papers often represent preliminary work and are circulated to encourage discussion. Citation of such a paper should account for its provisional character. A revised version may be available directly from the author. 
IZA Discussion Paper No. 4281

July 2009

\section{ABSTRACT}

\section{Flexible Labor Supply Models}

Discrete-choice models of labor supply have become very popular for ex ante evaluations of policy reforms as they easily account for non-convex budget sets. We test the constraints imposed in practice on these models and suggest a fully flexible model that significantly improves fit.

JEL Classification: H31, J22

Keywords: multinomial logit, labor supply, taxation

Corresponding author:

Olivier Bargain

University College Dublin

Newman Building

School of Economics

Dublin 4

Ireland

E-mail: olivier.bargain@ucd.ie

* This paper is forthcoming in Economics Letters. I am indebted for useful comments to François Bourguignon and Martin Browning. All errors or omissions remain mine. 


\section{Introduction}

Discrete-choice models are increasingly used to analyze labor supply responses to policy reforms as they easily deal with non-convexities in agents' budget sets (Blundell and MaCurdy, 2000). Indeed, tangency conditions are not required to hold as household objective functions are explicitly parameterized and maximized over a finite set of possibilities, corresponding to commonly agreed durations of work. In contrast to the continuous approach (Hausman and Ruud, 1984), discrete models impose in principle little constraint on preferences. In this note, we question whether these constraints are relaxed in practice.

To do so, we start from possibly the most flexible specification. Assume that utility derived by household $i$ from alternative $j(=1, \ldots, J)$ is given by:

$$
V_{i j}=U\left(C_{i j} ; Z_{i}, v_{i}, \theta_{j}\right)+\epsilon_{i j}
$$

It depends fundamentally on the level of household consumption $C_{i j}$ at choice $j$. In a static framework, this coincides with the disposable income obtained at $H_{j}$ hours of work, which is a complex function of labor income $w_{i} H_{j}$ (worker's wage rate time her labor supply), other (exogenous) incomes and household characteristics, typically approximated by tax-benefit microsimulation. Several effects are associated with the $j$-th alternative, including disutility attached to working $H_{j}$ hours (or utility: some individuals may be workaholics), specific costs of work, job search costs, etc. These different effects, captured by vector $\theta_{j}$, are not non-parametrically identified. They may vary with a vector $Z_{i}$ of household characteristics and with unobserved heterogeneity $v_{i}$.

This model retains the fundamental properties of structural models: (i) the assumption of utilitymaximizing behavior; (ii) the possibility to conduct welfare analysis (see Bargain, 2005); and (iii) the imposition of increasing monotonicity in consumption, which seem minimum requirements for meaningful policy analysis. ${ }^{1}$ Yet, 'preferences' $\theta_{j}$ may appear non-convex due to the presence of fixed costs, which militates in favor of relaxing usual regularity conditions on leisure/labor supply. ${ }^{2}$

In contrast, in recent applications, the set of parameters is not specific to the quantity of labor supplied, that is, $\theta_{j}=\theta$ for all $j$. Instead, utility varies with the quantity of labor $H_{j}$ as follows:

$$
V_{i j}=U\left(H_{j}, C_{i j} ; Z_{i}, v_{i}, \theta\right)+\epsilon_{i j}
$$

with $\theta$ coefficients interpreted as consumption-leisure preferences and typically specified using quadratic or translog functional forms. Compared to the 'unconstrained' model (U), standard models (S) necessarily introduce parameter restrictions across alternatives. Admittedly, the fit is often improved by addition of dummies for less common working hours (e.g., in van Soest, 1995 or Steiner and Wrohlich, 2004) or fixed costs of work (e.g., in Callan and van Soest, 1996, or Blundell et al., 2000), which capture the fact that there are very few observations with a small positive number of working hours. Yet, a fully non-parametric utility function is also able to pick up the gap in the distribution at few hours (van Soest et al., 2002), as is clearly the case with model $(\mathrm{U})$. Then, interpretation of the coefficients in terms of preferences or fixed costs can be pursued using (S)-models, but at the price of parametric restrictions (and possibly exclusion

\footnotetext{
${ }^{1}$ In our empirical application, C-monotonicity is respected for $96 \%$ of the households and imposed as a constraint in the likelihood maximization to achieve $100 \%$.

${ }^{2}$ Recent applications simply check a posteriori the quasi-concavity of preferences to avoid the MaCurdy critique (MaCurdy et al., 1990).
} 
restrictions on $Z_{i}$ variables). That is, identification rests on weak ground. Alternatively, it is possible to acknowledge these limitations and use the flexible model (U), which relaxes functional constraints and possibly improves fit. ${ }^{3}$ In the following, we conduct Likelihood Ratio (LR) tests of the (nested) model (S) against (U). Both models can be estimated as multinomial logit under the standard assumption that the i.i.d. error term $\epsilon_{i j}$ follows a I-EV distribution. The random component $v_{i}$ guarantees unrestricted substitution patterns between alternatives.

\section{Data and Specification}

From the French Household Budget Survey 1994/95, we select couples where adult members are in the age bracket $25-64$, not disabled, retired or a student, and neither self-employed nor job seeker. Since $97 \%$ of husbands are in work, we withdraw the remaining $3 \%$ households and model only female labor supply, treating male earnings as exogenous income. This choice is not atypical on French data (cf., Donni and Moreau, 2007). The final selection comprises 3,397 household and is described in Table 1. In France, institutional norms imply concentrations around a limited number of working time arrangements, as illustrated by Figure 1. Thus, we simply base our discretization on $J=5$ points corresponding to the main concentration points, that is $H_{j}=0,20,30,39,45$ hours a week. Alternatively, we suggest a discretization with $J=7$ points (adding 25 and 35-hour options to the previous set). Wages for inactive women are predicted using the traditional Heckman correction; the wage rate prediction errors are accounted for by integrating out the disturbance term of the wage equation in the likelihood (van Soest, 1995).

We suggest several specifications with increasing degrees of flexibility. A popular form in the literature consists of a quadratic utility completed with fixed costs of work $F_{i j}$ (e.g., Blundell et al., 2000). This model (S1) is written for choice $j=1, \ldots, J$ :

$$
U_{i j}=\alpha^{c c} \cdot\left(C_{i j}-F_{i j}\right)^{2}+\alpha^{h h} \cdot\left(H_{j}\right)^{2}+\alpha^{c h} \cdot\left(C_{i j}-F_{i j}\right) \cdot H_{j}+\alpha^{c}\left(Z_{i}, v_{i}\right) \cdot\left(C_{i j}-F_{i j}\right)+\alpha^{h}\left(Z_{i}\right) \cdot H_{j}
$$

with coefficients $\alpha^{c}$ and $\alpha^{h}$ varying linearly with household characteristics $Z_{i}$ (Paris area, number of children in age groups 0-2, 3-5 and 6-11 and parents' age) and $\alpha^{c}$ also varying with the random component $v_{i}$. Costs $F_{i j}$ are to be paid if labor supply is positive and vary with four household characteristics:

$$
\begin{aligned}
& F_{i 1}=0 \\
& F_{i j}=f^{0}+f^{1} \text { Paris }+f^{2} \text { Child } 02+f^{3} \text { Child } 35+f^{4} \text { Child } 611 \text { if } j>1 .
\end{aligned}
$$

In a variant (S2), we account for possible childcare costs by making the coefficient $f_{j}^{2}$ for children aged 0-2 vary freely with the labor supply alternative. This conforms to the fact that childcare costs typically increase with the working time of mothers of children in that age group. ${ }^{4}$ Note that variable costs of work

\footnotetext{
${ }^{3}$ Ideally, direct information about costs of work could be used, which is very rarely done in practice due to obvious data limitations. An exception is Blundell et al. (2000). Note that flexibility can also be increased by accounting for varying sets of hour-wage opportunities across individuals (Aaberge et al., 1995).

${ }^{4}$ For older children in France, full day childcare provided by public kindergarten (maternelles) is basically free and with unlimited supply.
} 
are rarely used in practice; an exception is Blundell et al. (2000), who conduct a separate estimation of childcare costs.

The unconstrained model $(\mathrm{U})$ is made comparable by use of the following quadratic form:

$$
U_{i j}=a_{j} \cdot C_{i j}^{2}+b_{j}\left(Z_{i}, v_{i}\right) \cdot C_{i j}+c_{j}\left(Z_{i}\right) \quad \text { for } j=1, \ldots, J
$$

with coefficients $b_{j}$ varying linearly with household characteristics $Z_{i}$ and the random component $v_{i}{ }^{5}$ and $c_{i j}$ varying quadratically with characteristics to mimic interactions between $\alpha^{c}$ and $F_{i j}$ in (S)models. Because disposable income $C_{i j}$ differs across alternatives, all coefficients $a$ and $b$ in $(2)$ can be identified. The econometric indeterminacy on the last coefficient is removed by setting it to zero for the first alternative. Parametric restrictions imposed by (S)-models on model (U) are explicitly derived in Bargain (2005).

Table 1: Descriptive Statistics for Selected Couples

\begin{tabular}{lcc}
\hline \hline & Women & Men \\
\hline Participation & 0.77 & 1 \\
Working time of participants (hours/week) & 34.7 & 41.9 \\
Gross wage rate - participant (euro/hour) & 11.7 & 13.7 \\
Gross wage rate - all potential workers (euro/hour)* & 11.0 & 41.1 \\
\hline Age & 38.9 & 0.18 \\
Primary education & 0.31 & 0.46 \\
Vocational training & 0.38 & 0.18 \\
High school diploma & 0.15 & 0.18 \\
University studies & 0.17 & \multicolumn{2}{c}{1.43} \\
\hline Average number of children & \multicolumn{2}{c}{0.17} \\
Presence of child 0-2 & \multicolumn{2}{c}{0.19} \\
Presence of child 3-5 & \multicolumn{2}{c}{0.33} \\
Presence of child 6-11 & \multicolumn{2}{c}{3,397} \\
\hline Number of observations & \multicolumn{2}{c}{$0,369,455$} \\
Weighted size of the sample & \multicolumn{2}{c}{0.28} \\
Size in \% of total population & \multicolumn{2}{l}{}
\end{tabular}

\section{Empirical Results}

Estimates are presented and discussed in Bargain (2005). They show in particular that interpreting the role of demographic characteristics is uneasy due to aforementioned identification issues in structural models. ${ }^{6}$ Fit and LR-tests are reported in Table 2. According to the pseudo- ${ }^{2}$, models (S1) and (S2) are outperformed by model $(\mathrm{U})$. LR-tests confirm that standard models are strongly rejected against the unconstrained specification. To balance fit and parsimony, we report the Akaike's information criterion (AIC): model (U) still dominates in spite of a larger number of parameters.

\footnotetext{
${ }^{5}$ Note that placing unobserved heterogeneity on the coefficient of disposable income is a natural choice to make (S)models and the unconstrained model (U) directly comparable. Also, to be fair in our comparison, the random component is not alternative-specific in (U). In other words, additional flexibility is placed only on the deterministic part of this model.

${ }^{6}$ For instance, the presence of young children affects simultaneously work preferences and cost of work; it may also affect the tax-benefit function.
} 


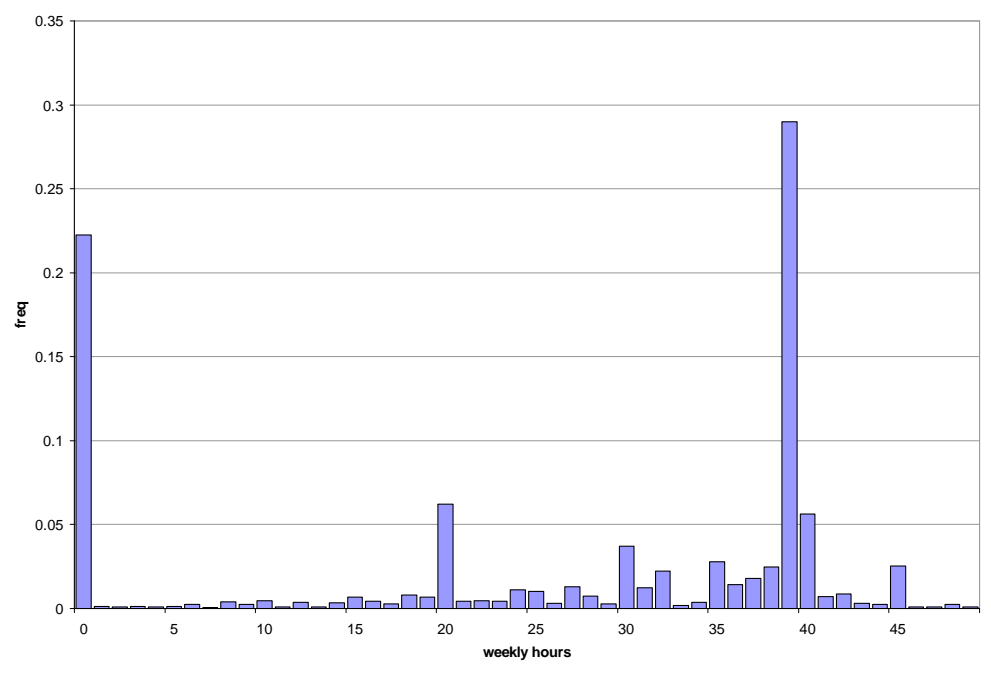

Figure 1: Distribution of Working Hours for Women with Employed Partners (selection)

However, model (U) bears the risk to capture idiosyncrasies of the data at use, especially because of the flexible way in which household characteristics $Z_{i}$ are introduced. We suggest a variant (U') which penalizes the model by forcing the interaction terms (the quadratic elements of $c_{j}\left(Z_{i}\right)$ ) not to vary with the labor supply alternatives. This restriction can be justified by practical limitations due to 'curse of dimensionality' problems. We use a standard validation method that consists in estimating each model on a random $60 \%$ of the sample and check model performance on the $40 \%$ holdout sample. We find that (S1) and (S2) are also rejected against (U'). When repeating the exercise for smaller holdout samples, sample size may be too small to assume a chi-squared distribution of the LR statistic; comparisons of pseudo- $\mathrm{R}^{2}$ nonetheless confirm that the unconstrained model (U') outperforms (S1) and (S2). These results seem to indicate that better performances are not driven by sampling-error overfitting but, instead, that model (U) better captures the complexity of labor supply behavior.

Finally, Table 3 illustrates the potential differences in model predictions for policy analysis. Wageelasticities are obtained by simulating a $+1 \%$ wage increase for all women of the sample. The policy reform corresponds to the introduction of an in-work benefit in France. Due to means-testing on joint income, this instrument discourages the labor supply of secondary earners (see Blundell et al., 2000, or Bargain, 2005, for more details). It appears that responses to wage shocks or policy reform are significantly larger when evaluated using the unconstrained model compared to model (S2). With a thinner discretization $(\mathrm{J}=7)$, responses are slightly but not significantly larger and, most importantly, the conclusions are identical, i.e., predictions of constrained and unconstrained models are significantly different. 
Table 2: Log-likelihoods and LR tests

\begin{tabular}{|c|c|c|c|c|c|c|c|}
\hline \multirow[b]{2}{*}{ Model } & \multirow[b]{2}{*}{ \# coefficients } & \multicolumn{3}{|c|}{ Fit } & \multicolumn{3}{|c|}{ LR tests } \\
\hline & & Log-likelihood & Pseudo-R2 & AIC & $\begin{array}{l}\text { nested by } \\
\text { model: }\end{array}$ & LR & $\operatorname{chi} 2(1 \%)$ \\
\hline \multicolumn{8}{|c|}{ Discretization with $J=5$ points } \\
\hline S1 & 25 & -4964 & $9 \%$ & 2.94 & $U$ & 1336 & 201 \\
\hline$\$ 2$ & 28 & -4876 & $11 \%$ & 2.89 & $U$ & 1160 & 197 \\
\hline$U$ & 181 & -4296 & $21 \%$ & 2.64 & - & - & - \\
\hline$U^{\prime}$ & 100 & -4345 & $20 \%$ & 2.62 & - & - & - \\
\hline \multicolumn{8}{|c|}{ Discretization with $J=7$ points } \\
\hline$S 1$ & 25 & -6016 & $9 \%$ & 3.56 & $U$ & 2006 & 295 \\
\hline$S 2$ & 30 & -5877 & $11 \%$ & 3.48 & $U$ & 1728 & 291 \\
\hline$U$ & 267 & -5013 & $24 \%$ & 3.11 & - & - & - \\
\hline$U^{\prime}$ & 132 & -5096 & $23 \%$ & 3.08 & - & - & - \\
\hline
\end{tabular}

Table 3: Wage Elasticities and Policy Effects

\begin{tabular}{|c|c|c|c|c|}
\hline \multirow{2}{*}{ Model } & \multicolumn{2}{|c|}{$1 \%$ increase in own wage } & \multicolumn{2}{|c|}{ In-work benefit reform } \\
\hline & $\begin{array}{l}\Delta \text { participation rate } \\
\text { (in ppt) }\end{array}$ & $\begin{array}{l}\Delta \text { average work hour } \\
\text { (in } \%)\end{array}$ & $\begin{array}{l}\Delta \text { participation rate } \\
\text { (in ppt) }\end{array}$ & $\begin{array}{l}\Delta \text { average work hour } \\
(\text { in } \%)\end{array}$ \\
\hline \multicolumn{5}{|c|}{ Discretization with $J=5$ points } \\
\hline \multirow[t]{2}{*}{$S 2$} & 0.14 & 0.20 & -0.46 & -0.62 \\
\hline & {$[0.11 ; 0.17]$} & {$[0.17 ; 0.25]$} & {$[-0.54 ;-0.37]$} & {$[-0.74 ;-0.50]$} \\
\hline \multirow[t]{2}{*}{$U$} & 0.20 & 0.31 & -0.79 & -1.08 \\
\hline & {$[0.17 ; 0.24]$} & {$[0.27 ; 0.37]$} & {$[-0.91 ;-0.65]$} & {$[-1.24 ;-0.88]$} \\
\hline \multicolumn{5}{|c|}{ Discretization with $J=7$ points } \\
\hline \multirow[t]{2}{*}{$S 2$} & 0.17 & 0.24 & -0.54 & -0.74 \\
\hline & {$[0.14 ; 0.20]$} & {$[0.20 ; 0.28]$} & {$[-0.62 ;-0.46]$} & {$[-0.86 ;-0.62]$} \\
\hline \multirow[t]{2}{*}{$U$} & 0.23 & 0.37 & -0.93 & -1.30 \\
\hline & {$[0.19 ; 0.26]$} & {$[0.31 ; 0.42]$} & {$[-1.06 ;-.79]$} & {$[-1.47 ;-1.12]$} \\
\hline
\end{tabular}

Note: labor supply responses are computed using averaged simulated transitions; figures in brackets give bootstrapped confidence intervals. 


\section{Conclusion}

This note shows that structural models currently used for policy evaluation may impose unnecessary constraints on household objective functions. Functional form restrictions also seem to affect the magnitude of predicted labor supply responses to tax-benefit reforms. We suggest a model where utility associated with the various hour choices depends on disposable income in a way that is totally independent across alternatives. Coefficients are considered as an evaluation of preferences in which work costs are already captured, so that regularity conditions on leisure are relaxed. The model maintains a strict utilitymaximizing interpretation and usual regularity conditions on consumption while significantly improving fit compared to standard specifications.

\section{References}

[1] Aaberge, R., J.K. Dagsvik and S. Strom (1995): "Labor Supply Responses and Welfare Effects of Tax Reforms", Scandinavian Journal of Economics, 97(4), 635-59.

[2] Bargain, O. (2005): "On modeling labour supply with taxation", IZA working paper

[3] Blundell, R.W. and T. MaCurdy (2000): "Labor Supply: A Review of Alternative Approaches", in Ashenfelter and Card (eds), Handbook of Labor Economics, Elsevier North-Holland.

[4] Blundell, R.W., A. Duncan, J. McCrae and C. Meghir (2000): "The Labour Market Impact of the Working Families' Tax Credit", Fiscal Studies, 21, 1, 75-103.

[5] Callan, T and A. van Soest (1996): "Family Labour Supply and Taxes in Ireland", ESRI working paper.

[6] Donni, O. and N. Moreau (2007): "Collective Labor Supply: A Single-Equation Model and Some Evidence from French Data.", Journal of Human Resource, 42(1), 214-246.

[7] Hausman, J.A. and P. Ruud (1984): "Family labor supply with taxes", American Economic Review, $74,242-248$.

[8] MaCurdy, T., D. Green and H. Paarsch (1990): "Assessing Empirical Approaches for Analysing Taxes and Labor Supply", Journal of Human Resources, 25, 415-490.

[9] Steiner, V. and K. Wrohlich (2004): "Household Taxation, Income Splitting and Labor Supply Incentives - A Microsimulation Study for Germany", CESifo Economic Studies, 50, 3, 541-568.

[10] van Soest, A. (1995): "Structural Models of Family Labor Supply: a Discrete Choice Approach", Journal of human Resources, 30, 63-88.

[11] van Soest, A., M. Das and X. Gong (2002): "A structural labor supply model with non-parametric preferences", Journal of Econometrics, 107 (1-2), 345-374. 